\section{Dennis Michael Krikler 1928-2016}

\section{Edward Rowland}

When Dennis Krikler completed his term of office as Editor of the British Heart Journal in 1992 the succeeding Editor, Professor Mike Davies, commissioned a Festscrift to acknowledge the achievements of his predecessor who had been at the helm of the journal for 11 years. The contents are a fascinating glimpse of the man, some of his cardiological achievements, certainly his wide-ranging interests and assuredly his international friendships. It is almost certainly the only time that the British Heart Journal has published an article entirely in French, a monologue by Phillipe Coumel who was one of the most original thinkers of modern arrhythmology and a scientific collaborator with Dennis.

Dennis Krikler was born in 1928 in South Africa. Most of his lifetime interests -cultural, medical, scientific, historical, and photographic-were rooted in the rich world of his childhood in the seaside resort of Muizenberg outside Cape Town where he lived for his first 28 years.

The childhood home, the house of his GP father, contained the surgery but pertinently his father had a special interest in cardiology and, unusually for a South African GP of that time, an electrocardiograph. An additional scientific influence in Muizenberg was the presence of a cardiologist, Dr Velva Schrire, who was both a patient of Dennis's father but also a friend, and who became Dennis's mentor. Schrire, who founded the Cardiac Clinic there on the principles he had learned as a registrar to Paul Wood at the National Heart Hospital in London, was the inspiration that led towards cardiology. Dennis studied medicine at the University of Cape Town Medical School, graduating in 1951, working first in Cape Town where he met a nurse at the Groote Schuur Hospital with strong interests in music and politics, Anne Winterstein. They were married in 1955

Completing his medical and cardiology training in England, Boston and back in South Africa he was encouraged by relatives in Rhodesia to come to their country. In 1958 he was appointed as cardiologist and lecturer in cardiology at a new medical school in Salisbury. The work was fascinating but the political climate fraught.

Correspondence to Dr Edward Rowland, Barts Heart Centre, St Bartholomew's Hospital, London, EC1A 7BE, UK; edward.rowland@bartshealth.nhs.uk
Dennis and his wife opposed the unilateral declaration of independence proclaimed by the government of Ian Smith in 1965 and this was noticed by the authorities: "The threat was that I would be restricted in the areas to which I could travel. This would cut me off from the University. It was a subtle way of making sure that I either shut up or got out".

The consequence was a move to England in 1966 where he re-kindled friendships he had made during his previous visit to London. After a series of clinical assistantships, Dennis obtained a consultant post at the Prince of Wales' Hospital in Tottenham. He became clinical tutor and set up the first UK course on ECGs for GPs. Sir John McMichael MD, who was the Director of the British Postgraduate Medical Federation, presided over the first of these and encouraged him to concentrate on electrocardiography. In 1973 he facilitated Dennis's move to the Royal Postgraduate Medical School.

These years were the beginning of the study of arrhythmia mechanisms by intracardiac electrophysiological study. Puech and Scherlag had demonstrated the possibility of recording the electrical activity of the specialised cardiac conduction system, and Durrer employed programmed stimulation to unearth the mechanisms of many rhythm abnormalities. Dennis's arrival in the UK caught this tide and he became a significant contributor to the development of clinical cardiac electrophysiology in the UK. His list of publications covered all aspects of rhythm abnormalities-mechanistic, therapeutic, interventional and pharmacological. The two papers published by the British Heart Journal in 1976 in collaboration with Phillipe Coumel on incessant tachycardia will still reward the inquisitive trainee with much that they need to know about the conductive and refractory interplay of the re-entry mechanism. The arrhythmia unit he created at the Hammersmith Hospital became a significant part of an outstandingly productive cardiac department.

Dennis was an armchair electrophysiologist-not for him the tortured hours spent obtaining vascular access or manipulating unruly catheters into seemingly inaccessible corners of the heart. Intellectually he was of the Vienna school of electrocardiography (Winternitz, Langendorf and Pick) whose deductive skill from surface electrocardiography recording had already deduced the mechanisms of so many rhythm abnormalities.

A gifted communicator Dennis increasingly turned his interest to the written and spoken word. He became assistant editor

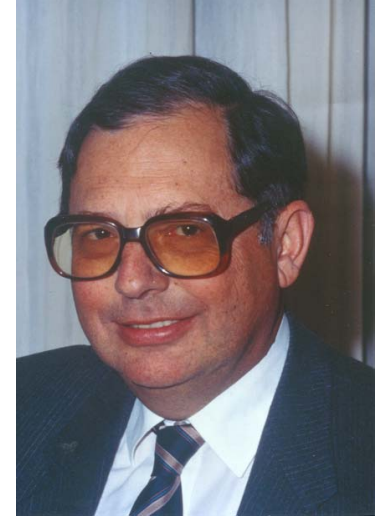

of the British Heart Journal under Walter Somerville and in 1981 he took over the editorship. His tenure was notable for developing review articles and an increased focus on postgraduate education. While he was a stickler for grammatical precision (no dangling particle or split infinitive ever escaped his eye) he was described by Stephen Lock, no amateur when it came to judging journal editors, as an outstanding clinician turned humble and creative editor-in other words the best type.

Dennis held several national and international professional positions. In the UK he served a treasurer of the British Cardiac Society where he argued strongly for the abolition of the 300 member limit. Dennis continued to develop his international contacts especially in the USA, where he completed 22 years on the editorial board of ACCEL, and in France. He developed a deep-seated affection for that country, its people and its cardiological sophistication. He did a great deal to further Franco-British Cardiological understanding and collaboration. This resulted in the award to Dennis of the Chevalier dans l'Ordre National de la Legion d'Honneur in 1999, an honour unprecedented in British cardiology.

Dennis Krikler is survived by his wife, daughter Shirley and son Paul.

\section{Competing interests None declared.}

Provenance and peer review Commissioned; internally peer reviewed.

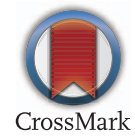

To cite Heart 2016;102:1150.

Heart 2016;102:1150.

doi:10.1136/heartjnl-2016-310121

\section{REFERENCE}

1 Dr Dennis M Krikler: editor of the British Heart Journa 1981-91. Br Heart J 1992;67:5-15. 